\title{
Erratum to: Contrasting effects of ocean acidification on reproduction in reef fishes
}

\author{
Megan J. Welch ${ }^{1,2} \cdot$ Philip L. Munday ${ }^{1}$
}

Published online: 13 April 2016

(C) Springer-Verlag Berlin Heidelberg 2016

\section{Erratum to: Coral Reefs}

\section{DOI 10.1007/s00338-015-1385-9}

The units on the ordinate in Fig. $3 \mathrm{~b}$ are milligrams. Similarly, the associated text in the "Methods" section should read, "Hatchling weight was measured (to $0.01 \mathrm{mg}$ ) as wet weight."
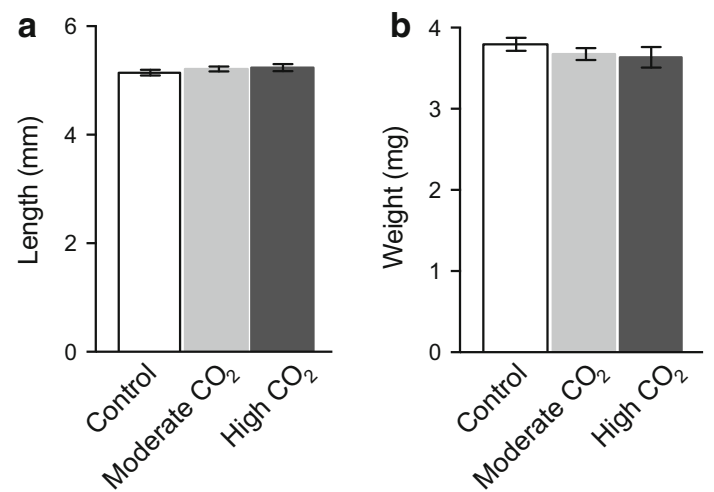

Fig. 3 Size of Acanthochromis polyacanthus hatchlings in control (white), moderate $\mathrm{CO}_{2}$ (light grey) and high $\mathrm{CO}_{2}$ (dark grey) treatments. a Standard length $(\mathrm{mm})$; b weight $(\mathrm{mg})$. Values are means of clutch averages $( \pm \mathrm{SE})$

The online version of the original article can be found under doi:10.1007/s00338-015-1385-9.

Megan J. Welch

meg.welch@my.jcu.edu.au

1 ARC Centre of Excellence for Coral Reef Studies, James Cook University, Townsville, QLD 4811, Australia

2 College of Marine and Environmental Sciences, James Cook University, Townsville, QLD 4811, Australia 